\title{
Investigation of meticillin-resistant Staphylococcus aureus in pigs used for research
}

Correspondence

Pierce K. H. Chow

gsupc@singnet.com.sg

Received 12 March 2007

Accepted 26 April 2007

\author{
Darvi Michell Bufete Sergio, ${ }^{1}$ Tse Hsien Koh, ${ }^{2}$ Li-Yang Hsu, ${ }^{3}$ \\ Bryan Emmett Ogden, ${ }^{1,4}$ Angela L. H. Goh ${ }^{1}$ and Pierce K. H. Chow ${ }^{1}$
}

\author{
${ }^{1}$ Department of Experimental Surgery, Singapore General Hospital, Singapore 169608, Singapore \\ ${ }^{2}$ Department of Pathology, Singapore General Hospital, Singapore 169608, Singapore \\ ${ }^{3}$ Department of Internal Medicine, Singapore General Hospital, Singapore 169608, Singapore \\ ${ }^{4}$ Maccine Pte Ltd, Singapore Science Park II, Singapore 117684, Singapore
}

\begin{abstract}
Meticillin-resistant Staphylococcus aureus (MRSA) was unexpectedly isolated from a pig used for streptozotocin-induced diabetes research. To investigate the possible source of the MRSA isolate, nasal swabs were obtained from the animal herd, and from animal holding rooms, and veterinary and research staff involved in the handling of the animals. Overall, four MRSA isolates were cultured from three pigs and from a clinician/scientist. Two were ST22-MRSA-IV, a human strain type associated with epidemic spread. The other two were ST398-MRSA-V, a strain type associated with pigs. Thus, care should be taken to prevent cross-transmission of MRSA.
\end{abstract}

\section{INTRODUCTION}

Meticillin was introduced into clinical practice in 1960 and meticillin-resistant Staphylococcus aureus (MRSA) was described 1 year later (Jevons, 1961). Since then, MRSA has become a major human pathogen, responsible for considerable mortality, morbidity and healthcare expenditure in both nosocomial and community settings (Chambers, 2001; Fey et al., 2003; Haddadin et al., 2002).

Although rarely reported in the past, the prevalence of MRSA in pigs, along with cases of possible pig-to-human transmission and vice versa, have been the subject of considerable and increasing interest over the past 2 years (Armand-Lefevre et al., 2005; Huijsdens et al., 2006; Voss et al., 2005).

In August 2005, MRSA was unexpectedly isolated from a pig used for streptozotocin-induced diabetes research in the Department of Experimental Surgery, Singapore General Hospital. The animal had a skin abscess from a surgical incision site and was administered enrofloxacin to treat infection. Unfortunately, the animal failed to respond to treatment, developed sepsis, lost $20 \%$ of its body weight and was euthanized. MRSA was isolated from a bile specimen sent for bacterial culture taken post-mortem.

To investigate the possible source of the MRSA isolate and to determine whether there was an outbreak in the animal research facility, nasal swabs were obtained from the

Abbreviations: MLST, multilocus sequence typing; MLVA, multilocus variable number tandem repeat analysis; MRSA, meticillin-resistant Staphylococcus aureus; MSSA, meticillin-sensitive Staphylococcus aureus. animal herd and animal holding rooms, and from veterinary and research staff involved in the handling of the animals. Samples were also taken from the Animal Laboratory Centre of the National University of Singapore and from a slaughterhouse that was housing pigs of the same source as the department.

\section{METHODS}

Samples. Samples were taken from a Landrace/Yorkshire crossbreed of mixed ages and sex $(40-180 \mathrm{~kg})$. Nasal swabs were obtained from the animal herd $(n=50)$ and animal holding rooms $(n=14)$ of the Singapore General Hospital, Department of Experimental Surgery, Sembawang Farm and the Animal Research Facility, National University of Singapore Animal Laboratory Centre $(n=8)$, and the slaughterhouse of Primary Industries Pte Ltd, Singapore $(n=50)$. Human nasal swab isolates were obtained from veterinary staff $(n=23)$, research staff $(n=6)$ and animal laboratory staff $(n=3)$ (see Table 2).

Experimental procedures. Nasal swab isolates were plated on to MRSA screening plates containing Mueller-Hinton agar with $6 \mu \mathrm{g}$ oxacillin $\mathrm{ml}^{-1}$ and $4 \% \mathrm{NaCl}$. Bacteria were identified by positive slide and tube coagulation tests, the API Staph system, and universal 16S rRNA gene amplification and sequencing. Susceptibility to ciprofloxacin, erythromycin, clindamycin, tetracycline, gentamicin, rifampicin and vancomycin was tested using the Kirby-Bauer disc diffusion method and following the Clinical and Laboratory Standards Institute (formerly the National Committee for Clinical Laboratory Standards) guidelines (NCCLS, 2005). The staphylococcal chromosome cassette mec (SCCmec) type was determined using methods described by Ito et al. (2004). All MRSA isolates were similarly typed by PFGE with SmaI using standard methods, and multilocus sequence typing (MLST) was performed as described by Enright et al. (2000). To determine the relationship of the MRSA 
Table 1. Antibiogram of the recovered MRSA from pigs and a clinician scientist

\begin{tabular}{|c|c|c|c|c|c|c|c|c|c|c|}
\hline \multirow[t]{2}{*}{ MRSA } & \multirow[t]{2}{*}{ ST } & \multirow[t]{2}{*}{ PFGE profile } & \multirow[t]{2}{*}{ SCCmec type } & \multicolumn{7}{|c|}{ Antimicrobial susceptibility } \\
\hline & & & & CIP & E & CC & TE & GM & RFB & VA \\
\hline Pig 1 & 398 & $\mathrm{~N}$ & $\mathrm{~V}$ & $\mathrm{R}$ & $\mathrm{S}$ & $\mathrm{R}$ & $\mathrm{R}$ & S & S & $S$ \\
\hline Clinician scientist & 22 & $\mathrm{~B}$ & IV & $\mathrm{R}$ & $\mathrm{R}$ & $\mathrm{Ri}$ & S & S & S & $\mathrm{S}$ \\
\hline Pig 2 & 22 & B & IV & $\mathrm{R}$ & $\mathrm{R}$ & $\mathrm{Ri}$ & S & S & S & $\mathrm{S}$ \\
\hline Pig 3 & 398 & $\mathrm{~N}$ & $\mathrm{~V}$ & $\mathrm{R}$ & $\mathrm{R}$ & $\mathrm{R}$ & $\mathrm{R}$ & S & S & $S$ \\
\hline
\end{tabular}

ST, Sequence type; CIP, ciprofloxacin; E, erythromycin; CC, clindamycin; TE, tetracycline; GM, gentamicin; RFB, rifampicin; VA, vancomycin; R, resistant; Ri, intermediate resistant; S, susceptible.

isolates to clinical isolates in Singapore, multilocus variable number tandem repeat analysis (MLVA) was performed (Sabat et al., 2003). Virulence gene profiling was also carried out to assess the risk of human infection posed by the isolates (Jarraud et al., 2002).

\section{RESULTS AND DISCUSSION}

The first pig MRSA isolate was resistant to clindamycin and ciprofloxacin, but susceptible to erythromycin and gentamicin (Table 1). This isolate possessed SCCmec type V. Following PFGE with SmaI, the isolate produced a smear across the gel lane rather than discrete bands, which is consistent with the description of non-typable $S$. aureus by Voss et al. (2005) and Huijsdens et al. (2006). The MLVA results did not match any of the other MRSA isolates in our national database. However, the MLST results revealed that the isolate belonged to ST398 (3-35-19-2-20-26-39). This sequence type is unique in Singapore and, along with the unusual antibiogram, suggested that the organism was likely to have originated from the pig rather than from a human source. Virulence gene profiling also revealed that the first pig MRSA isolate only possessed one toxin gene, $\gamma$ haemolysin, and was negative for all other toxin genes.

Among 93 isolates cultured during the initial sampling of pigs and humans, 1 pig imported from a commercial farm in Pulau Bulan, Indonesia, and a clinician scientist tested positive (Table 2). Although the two were never in direct contact, the results showed that the isolate was identical and belonged to ST22-MRSA-IV, also known as UK-EMRSA-15. A study on the dissemination of multisusceptible MRSA (susceptible to aminoglycosides, trimethoprim-sulfamethoxazole and tetracycline) in Singapore hospitals has revealed that this strain has recently been increasing in the hospital population (Hsu et al., 2005).

As the two ST22 isolates were unrelated and independent of the first case of MRSA, and both pigs with MRSA had been imported from a commercial farm in Pulau Bulan, Indonesia, further sampling was performed in the Animal Laboratory Centre of the National University of Singapore and in the slaughterhouse. Both sites were housing pigs from the same source. Of the total 58 nasal swab isolates from pigs and 3 from humans, 1 pig was positive for MRSA whilst none of the human samples were positive (Table 2).
Upon typing, the isolate matched the SCCmec type, MLVA type and MLST of the first pig case, but had a slightly different antibiogram. The latter was resistant to erythromycin and susceptible to gentamicin, whilst the former was susceptible to both drugs (Table 1).

Overall, four MRSA isolates were identified: three from pigs from Pulau Bulan, Indonesia, and one from a clinician/scientist involved in the handling of the first pig case of MRSA.

Although the exact source of the first clinical isolate was never fully determined, it is likely to have originated from pigs imported from Indonesia, and did not seem to have spread to other pigs or humans in the department. The first and third strain isolated belonged to ST398, which is quite rare. There are two records in the MLST database, a meticillin-sensitive $S$. aureus (MSSA) isolate from a human nasal exudate in Cape Verde in 1997 and an MRSA isolate

Table 2. Results of MRSA and MSSA isolates from pigs and humans

\begin{tabular}{|lccc|}
\hline & $\begin{array}{c}\text { No. of } \\
\text { samples }(\boldsymbol{n})\end{array}$ & $\begin{array}{c}\text { No. of } \\
\text { MSSA }\end{array}$ & $\begin{array}{c}\text { No. of } \\
\text { MRSA }\end{array}$ \\
\hline $\begin{array}{l}\text { Initial sampling } \\
\text { Pigs }\end{array}$ & & & \\
$\quad$ Animal herd & 50 & 0 & 0 \\
$\quad$ Animal holding rooms & 14 & 0 & 1 \\
Humans & & & \\
$\quad$ Veterinary staff & 23 & 8 & 0 \\
$\quad$ Researchers & & & \\
$\quad$ Clinician scientist & 2 & 1 & 1 \\
$\quad$ Research staff & 4 & 0 & 0 \\
Total & $\mathbf{9 3}$ & $\mathbf{9}$ & $\mathbf{2}$ \\
$\quad$ Second sampling & & & \\
Pigs $\quad$ & 8 & 0 & 0 \\
$\quad$ Animal lab centre & 50 & 0 & 1 \\
$\quad$ Slaughterhouse & & & \\
Humans & 3 & 0 & 0 \\
$\quad$ Animal laboratory staff & $\mathbf{6 1}$ & $\mathbf{0}$ & $\mathbf{1}$ \\
Total & & & \\
\hline
\end{tabular}


from a human source in The Netherlands in 2003 (www.mlst.net).

Recently, reports in France and The Netherlands have shown the presence of MRSA in pigs, pig farmers and human controls (Armand-Lefevre et al., 2005; Huijsdens et al., 2006). Although some MLST sequence types were also found in human controls, ST398 was among those found only in pigs and pig farmers. It therefore seems likely that there is an association of this particular MLST type with pigs.

However, there was an implication that the second case of MRSA (ST22) in the pig could have been acquired from a human source. The pig had only been in contact with the veterinary staff of the department's holding unit and none of the other staff or researchers. Although all veterinary staff tested negative, it is possible that a clinician scientist who had the same strain as the pig could have contaminated the area. Clinician scientists move in and out of the facility and are distinct from the regular staff. Unfortunately, this could not be confirmed, as there were no samples collected from the departments' procedure areas and operating theatres. However, recent reports in veterinary hospitals suggest that, if MRSA is predominant in the environment, there is a risk of infection (Weese et al., 2004). Thus, the pig could have acquired the infection whilst undergoing a procedure.

The reasons for the emergence of MRSA in the swine population remain uncertain. Recent publications proposed that there is a high risk of exposure for humans working with pigs and it is possible that strain exchange occurs between them on a large scale (Armand-Lefevre et al., 2005; Huijsdens et al., 2006; Voss et al., 2005). It could also be due to increased exposure of animals to MRSA-infected people (Loeffler et al., 2005; Weese et al., 2005).

The isolation of the three strains from different pigs provides evidence that MRSA is a problem not only in hospitals but also in the veterinary field. It demonstrates that possible risks are involved in pigs used for experimental studies, as they may be potential recipients and sources of MRSA. This also has wider implications for research and for the development of treatment modalities in humans, as pigs are widely used in many types of biomedical research.

\section{ACKNOWLEDGEMENTS}

Special thanks are given to the following, who made this paper possible: the entire staff of the Department of Experimental Surgery of Singapore General Hospital, particularly to Mr Robert Ng, Senior Manager, and to Dr Jason Villano; Mr Koh Eng Yeong, Head, Abattoir and Poultry Slaughterhouse Inspection Branch of the Agrifood and Veterinary Authority of Singapore; and to Mr Wong Fock Nam, Senior Manager, Primary Industries Pte Ltd; the staff of the Animal Laboratory Centre of the National University of Singapore for providing us with the additional samples for the study; as well as to the staff of the Microbiology Laboratory of Singapore General Hospital for their help in the isolation of our MRSA strains.

\section{REFERENCES}

Armand-Lefevre, L., Ruimy, R. \& Andremont, A. (2005). Clonal comparison of Staphylococcus aureus isolates from healthy pig farmers, human controls and pigs. Emerg Infect Dis 11, 711-714.

Chambers, H. F. (2001). The changing epidemiology of Staphylococcus aureus? Emerg Infect Dis 7, 178-182.

Enright, M. C., Day, N. P. J., Davies, C. E., Peacock, S. J. \& Spratt, B. (2000). Multilocus sequence typing for characterization of methicillin-resistant and methicillin susceptible clones of Staphylococcus aureus. J Clin Microbiol 38, 1008-1015.

Fey, P. D., Salid-Salim, B., Rupp, M. E., Hinrichs, S. H., Boxrud, D. J., Davis, C. C., Kreiswirth, B. N. \& Schlievert, P. M. (2003). Comparative molecular analysis of community- or hospital-acquired methicillinresistant Staphylococcus aureus. Antimicrob Agents Chemother 47, 196-203.

Haddadin, A. S., Fappiano, S. A. \& Lipsett, P. A. (2002). Methicillin resistant Staphylococcus aureus (MRSA) in the intensive care unit. Postgrad Med J 78, 385-392.

Hsu, L.-Y., Koh, T. H., Singh, K., Kang, M. L., Kurup, A. \& Tan, B. H. (2005). Dissemination of multisusceptible methicillin-resistant Staphylococcus aureus in Singapore. J Clin Microbiol 43, 2923-2935.

Huijsdens, X. W., van Dijke, B. J., Spalburg, E., van SantenVerheuvel, M. G., Heck, M. E. O. C., Pluister, G. N., Voss, A., Wannet, W. J. B. \& de Neeling, A. J. (2006). Community-acquired MRSA and pig farming. Ann Clin Microbiol Antimicrob 5, 26.

Ito, T., Ma, X. X., Takeuchi, F., Okuma, K., Yuzawa, H. \& Hiramatsu, K. (2004). Novel type staphylococcal cassette chromosome mec driven by a novel cassette chromosome recombinase, ccrC. Antimicrob Agents Chemother 48, 2637-2651.

Jarraud, S., Mougel, C., Thioulouse, J., Lina, G., Meugnier, H., Forey, F., Nesme, X., Etienne, J. \& Vandenessch, F. (2002). Relationship between Staphylococcus aureus genetic background, virulence factors, agr groups (alleles) and human disease. Infect Immun 70, 631-641.

Jevons, M. P. (1961). Celbenin-resistant staphylococci. BMJ i, $124-125$.

Loeffler, A., Boag, A. K., Sung, J., Lindsay, J. A., Guardabassi, L., Dalsgaard, A., Smith, H., Stevens, K. B. \& Lloyd, D. H. (2005). Prevalence of methicillin-resistant Staphyloccocus aureus among staff and pets in a small animal referral hospital in the UK. $J$ Antimicrob Chemother 56, 692-697.

NCCLS (2005). Performance Standards for Antimicrobial Susceptibility Testing, 14th informational supplement, M100-S15. Wayne, PA: National Committee for Clinical Laboratory Standards.

Sabat, A., Krzyszton-Russjan, J., Strzalka, W., Filipek, R., Kosowska, K., Hryniewicz, W., Travis, J. \& Potempa, J. (2003). New method for typing Staphylococcus aureus strains: multiple-locus variable tandem repeat analysis of polymorphism and genetic relationships of clinical isolates. $J$ Clin Microbiol 41, 1801-1804.

Voss, A., Loeffen, F., Bakker, J., Klaassen, C. \& Wulf, M. (2005). Methicillin-resistant Staphylococcus aureus in pig farming. Emerg Infect Dis 11, 1965-1966.

Weese, J. S., Dacosta, T., Button, L., Goth, K., Ethier, M. \& Boehnke, K. (2004). Isolation of methicillin-resistant Staphylococcus aureus from the environment in a veterinary teaching hospital. J Vet Intern Med 18, $468-470$.

Weese, J. S., Archaumbault, M., Willey, B. M., Dick, H., Hearn, P., Kreiswirth, B. N., Said-Salim, B., McGeer, A., Lkihoshvay, Y. \& other authors (2005). Methicillin-resistant Staphylococcus aureus in horses and horse personnel, 2000-2002. Emerg Infect Dis 11, 430-435. 